\title{
TranSFORMAÇÕES SOCIAIS E ECONÔMICAS E A MUDANÇA NA CONFIGURAÇÃO DO CAMPO POLÍTICO LOCAL NO MUNICÍPIO DE Caraguatatuba (SP)
}

\author{
Samuel Candido de Souza ${ }^{1}$
}

\begin{abstract}
Resumo
0 campo político, como todos os outros campos sociais, recebe influências do mundo exterior, o que torna possível a vida política. Mudanças sociais e econômicas alteram a forma como o campo político se apresenta, ao modificar as condições para 0 acesso e 0 sucesso dentro dele. Esse artigo procura analisar como as transformações sociais e econômicas sofridas pelo município de Caraguatatuba, no período correspondente aos anos de 1970 a 2000, alteraram o perfil social dos principais agentes políticos locais, enfatizando os processos de inserção política de agentes sociais no que se refere aos mecanismos de reconversão de recursos sociais em capital político.
\end{abstract}

Palavras-chave: Poder local. Capital político. Recrutamento de agentes políticos. Mudanças socioeconômicas.

\section{SOCIAL AND ECONOMIC TRANSFORMATIONS AND THE CHANGE IN LOCAL POLITICAL CONFIGURATION IN CARAguatatuba (SP) Abstract}

The political field, as any other social fields, is influenced by the outside world, which enables political life. By changing access and success conditions, social and

\footnotetext{
${ }^{1}$ Doutorandoem CiênciaPolítica,UniversidadeFederaldeSãoCarlos, Brasil.samuelcandidosouza@ gmail.com
} 
economic changes alter the way the political field is portrayed. This paper tries to analyze how social and economic transformations in Caraguatatuba, between 1970 and 2000, changed the social profile of the main local political agents, emphasizing the processes of political inclusion of social agents in regard to the mechanisms of reconverting social resources into political capital.

Keywords: Local government. Political capital. Recruitment of political agents. Socioeconomic changes.

\section{INTRODUÇÃO}

onforme argumenta Bourdieu (1989), como todos os outros campos sociais, o campo político pode ser descrito enquanto um espaço multidimensional de coordenadas onde os agentes se posicionam na primeira dimensão de acordo com o volume total de capital que possuem e, na segunda dimensão, de acordo com o peso relativo dos capitais que possuem. Os capitais são as propriedades que dão poder ao seu portador dentro deste campo, e podem estar em forma de bens materiais ou em estado incorporado (como no caso de títulos escolares ou notoriedade). Nesse sentido, são os recursos manipuláveis pelos agentes dentro do campo que constituem seu capital político, sendo tais recursos adquiridos dentro do próprio campo político ou oriundos de reconversões de capitais adquiridos em outras esferas, como o capital econômico propriamente dito, notoriedade social, relações estabelecidas em função de sua ocupação profissional, etc. Uma das considerações de Bourdieu acerca do campo político é que, diferentemente de outros campos sociais, ele não é fechado em si, ou seja, o mundo exterior ao campo tem certa influência dentro dele porque, de outra forma, a vida política seria impossível. Tal influência se dá, sobretudo, pelo fato do poder atribuído aos políticos ser, em certa medida, a eles delegados por um grupo, como também pelo fato de serem periodicamente julgados pelos eleitores.

Partindo deste argumento, a formação do campo político local depende das características sociais e econômicas da localidade em questão, no sentido de que elas impõem certas condições para a entrada no campo político e para 0 sucesso dentro dele, condições tais que obrigam os agentes políticos a adquirirem determinados tipos de capital, favorecendo o recrutamento nos estratos sociais que possuem maiores possibilidades de acesso a esses capitais, conformando um determinado perfil social de elite política. Pela mesma lógica, as transformações 
sociais e econômicas que tal localidade vier a sofrer terão reflexos no perfil social da elite política, por modificar as condições de entrada e de sucesso do campo político.

Neste artigo procuro demonstrar de que maneira as transformações de ordem social e econômica sofridas pelo município de Caraguatatuba no período correspondente aos anos de 1970 a 2000, como também transformações de ordem institucional ocorridas, sobretudo, após o processo de redemocratização, alteraram a configuração do campo político local e levaram a uma grande mudança no perfil social dos principais agentes políticos, em especial dos vereadores eleitos no período. Trata-se não simplesmente de constatar que um fenômeno produz o outro, mas de compreender como os elementos que constituem o primeiro fenômeno se combinam e interagem, criando os fatores condicionantes para o desenvolvimento do segundo fenômeno.

\section{ELEMENTOS PARA A ANÁLISE DO PERFIL SOCIAL DOS AGENTES POLÍTICOS}

Segundo Fisher (apud SILVA, 2008, p. 70), há duas ideias complementares naquilo que envolve a noção de poder local: enquanto um âmbito espacial delimitado, o "local" pode significar base, território, microrregião, etc., designações que sugerem constância e certa inércia. Por outro lado, a mesma ideia sugere a existência de um espaço abstrato de relações sociais que se deseja privilegiar, indicando, portanto, movimento e interação de grupos sociais que se articulam e se opõem em relação a interesses comuns. Ao delimitarmos Caraguatatuba não nos referimos apenas ao território ocupado pelo município ou à sua localização geográfica, procuramos indicar também e principalmente as relações de força pelas quais se processam alianças e conflitos entre agentes sociais e a formação de identidades políticas específicas. Assim, Caraguatatuba não seria apenas um espaço físico, mas também um conjunto de redes estruturadas em torno de interesses específicos.

Os estudos clássicos sobre o tema do poder local no Brasil ${ }^{2}$ enfatizam, sobretudo, a proeminência de um mandatário local, possuidor de recursos econômicos e sociais que the permitia controlar um vasto contingente de pessoas

\footnotetext{
${ }^{2}$ Dentre os estudos clássicos sobre o poder local no Brasil, destacamos Queiroz (1969) e Leal (1975). Vale destacar também os estudos de Love (1982) sobre a composição social das elites políticas paulista e de Dean (1977) sobre o município de Rio Claro (SP).
} 
e se firmar como mediador da localidade frente às outras esferas de governo, num contexto social eeconômico caracterizado pelo baixo índicede urbanização, relativo isolamento das localidades, alta concentração fundiária, relações tradicionais de produção, etc., características dos municípios interioranos até meados da década de 1960. 0 avanço da urbanização e a modernização da agricultura, que inseria formas capitalistas de relação entre trabalhadores rurais e proprietários, alteram os padrões de dominação política e de interação entre esses municípios e os governos estadual e federal foram redefinidos. Essa nova realidade traz à tona novos grupos sociais, ligados à indústria e ao comércio, portadores de reivindicações políticas próprias, que diluem o poder do mandatário e permitem a emergência de outros agentes que disputar-lhes-iam o predomínio da mediação política³.

Assim, há necessidade de uma nova abordagem acerca dos processos políticos em âmbito local que englobe toda a complexidade das relações construídas neste novo ambiente até certo ponto volátil, refletindo na forma como os novos agentes políticos se organizam para disputar o poder. Para Coradini (2008), é preciso ampliar o campo de análise, sair das dimensões institucionais e passar a utilizar informações relativas às facções, redes, biografias, estruturas de mediação, etc. Trata-se, de acordo com o autor, de verificar as possibilidades de reconversão de bases sociais (tais como origem familiar e social, formação escolar, acúmulo de relações sociais, trajetórias profissionais e políticas e origem geográfica) em recursos políticos. 0 objeto de estudo deixa de ser grupos ou indivíduos específicos e sim os recursos e os princípios de legitimação que estruturam suas práticas e, inclusive, suas relações com as demais categorias sociais, não necessariamente dominantes. Em outras palavras, o estudo das elites políticas passa pela análise da maneira como os agentes políticos se inserem, se posicionam e se movimentam dentro do campo político local.

Nesse sentido, a lógica do recrutamento de agentes políticos está relacionada ao conjunto dos capitais importantes para o sucesso político, o que favorece os grupos sociais que detém tais capitais. Assim, mudanças sociais e econômicas, ao alterarem o conjunto dos capitais importantes, possibilitam mudanças no perfil social dos principais agentes políticos ao alterar as condições de acesso ao campo político. Porém não é algo automático, pois a maneira como as mudanças sociais

\footnotetext{
${ }^{3}$ Sobre este tema, especialmente em relação às transformações políticas no interior do estado de São Paulo, ver Kerbauy (2000).
} 
e econômicas se combinam, além das próprias disposições inerentes ao campo político, definem o grau e a intensidade das mudanças no perfil da elite política.

\section{Caraguatatuba: CARACTERÍSTICAS SOCIAIS, ECONÔMICAS E POLÍTICAS}

Caraguatatuba é um município localizado no litoral norte do estado de São Paulo, distante 186 Km da Capital, com uma população de aproximadamente 96.000 habitantes segundo estimativa do IBGE para o ano de 2009. Sua localização privilegiada faz dela a principal porta de entrada para o litoral norte paulista, através da Rodovia dos Tamoios (SP-99), ligando-a à região do Vale do Paraíba.

Figura 1 - Caraguatatuba - Localização

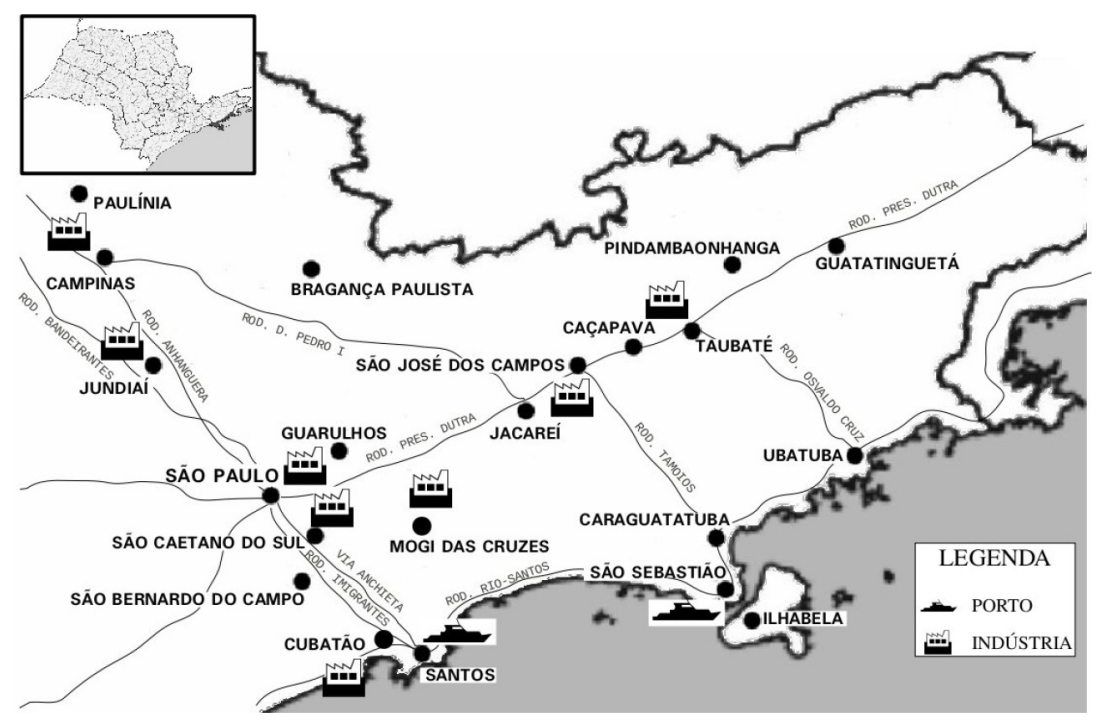

Fonte: Autor

Como toda a região do Litoral Norte paulista, Caraguatatuba esteve praticamente isolada das demais regiões, o que explicaria sua pequena população e sua economia estagnada na primeira metade do século XX. Apenas em meados da década de 1950 esse isolamento é rompido pelas obras de ampliação e modernização do porto de São Sebastião, necessárias para desafogar o porto de Santos. Nesse período são canalizados investimentos para o Litoral Norte, 
principalmente para melhorias na infraestrutura urbana e nas vias de acesso terrestres ${ }^{4}$, possibilitando à região a emergência do turismo como principal atividade econômica, cujos efeitos são sentidos, mormente, a partir da década de 1970, reflexos do "milagre brasileiro", que impulsionou o setor imobiliário local relacionado ao turismo de segunda residência (a "casa na praia"). Para se ter uma ideia, dos loteamentos aprovados de 1945 até 1990, 50\% foram entre 1974 e 1982. 0 turismo de segunda residência acabou por moldar a economia do município, cujas principais características são:

- Preponderância do setor terciário, com comportamento caracterizado pela sazonalidade e com forte presença de empregos informais;

- Setor industrial voltado principalmente para a extração e transformação de minerais não metálicos e outros ramos de atividades voltados para construção civil;

- Agropecuária pouco expressiva, tanto em nível local quanto no conjunto do estado.

Nesse período ocorre o crescimento do setor de serviços, principalmente aqueles voltados à atividade turística, além da construção civil, ligado ao "boom" imobiliário. Destacam-se também os serviços de compra e venda, loteamento e incorporação, administração e arrendamento de bens imóveis. Por outro lado, ocorre também uma grande especulação, com a imobilização de capitais em terras e a consequente diminuição da superfície agrícola do município.

Em relação às características populacionais, o que chama a atenção em Caraguatatuba foram o rápido processo de urbanização e o aumento populacional, sobretudo na década de 1970. Quanto ao primeiro aspecto, de um município com características rurais, possuindo mais da metade da população no campo em 1960, Caraguatatuba passa a ter cerca de 87\% da população morando na área urbana já em 1970, índice que chegaria a 98\% em 1980. Pode-se atribuir tanto ao turismo como à atividade portuária as causas desse fenômeno, sendo a vida urbana resultado da especialização econômica relacionada à prestação de serviços voltados ao turismo, além de serviços públicos e de infraestrutura. Quanto ao segundo aspecto, os dados apontam um acentuado e constante aumento

\footnotetext{
${ }^{4}$ Em relação à atividade portuária como fator para o desenvolvimento do Litoral Norte, ver Secretaria do Meio Ambiente (SÃo PAUL0, 1996, p. 91); Instituto de Pesquisas Tecnológicas de São Paulo (2000, p. 6-5).
} 
populacional ao longo das três décadas, com a população saltando de 14.862 em 1970 para 78.544 em 2000. Este fenômeno relaciona-se ao mecanismo de animação econômica do município, cujas atividades estão vinculadas ao setor de serviços e de construção civil. Até a década de 1960, o crescimento demográfico se fundamentava basicamente no componente vegetativo, enquanto que na década seguinte o componente migratório passou a explicar o incremento populacional. Em comparação aos outros municípios da região, Caraguatatuba possui um índice de incremento migratório da ordem de 65,67\%, menor apenas que Guararema (79,35\%), município integrante da Grande São Paulo, porém maior que São José dos Campos, Jacareí, Taubaté e Tremembé, municípios que concentram as principais indústrias no Vale do Paraíba. Em Ubatuba, outro município do Litoral Norte, o mesmo índice foi de 49,13\% (PROJETO MAVALE apud SÃO PAULO, 1996).

Em termos políticos, podemos notar três momentos distintos. 0 primeiro, na década de 1970, é marcado pelo predomínio absoluto da Arena como a única forma de participação em nível partidário. Como Caraguatatuba era um município carente de recursos e com enormes necessidades de obras para a ampliação de sua infraestrutura urbana a fim de acomodar a crescente população, agravado ainda pela necessidade de reconstrução dos estragos provocados pela tragédia de $1967^{5}$, ser filiado ao partido governista em um regime ditatorial era fundamental para acessar às esferas estadual e federal e obter recursos ${ }^{6}$. E, por essa mesma razão, vários órgãos estaduais tiveram atuação diversa e constante no município neste período, sobretudo a Sudelpa.

o campo político local era extremamente estreito, com duas facções lutando de todas as maneiras para vencer as eleições para a Prefeitura e Câmara

\footnotetext{
${ }^{5}$ Uma precipitação excepcional de água, caindo cerca de $580 \mathrm{~mm}$ de chuva em dois dias, quase a metade da média de chuvas que caem no Brasil em um ano $(1.200 \mathrm{~mm})$, encharcando o solo dos morros circundantes de tal modo que provocou uma verdadeira avalanche de lama, pedras e árvores, atingindo quase toda a extensão do município, arrasando a periferia e destruindo quase a totalidade da cidade. Mais de 30 mil árvores ficaram espalhadas em volta da cidade, cerca de 3.000 pessoas ficaram desabrigadas (de uma população de 15.000 habitantes na época) e foram contabilizadas 500 mortes, porém esse número provavelmente foi muito maior devido à quantidade de pessoas que foram soterradas ou arrastadas para o mar pela avalanche.

${ }^{6} 0$ diretório municipal do MDB só foi aberto em meados de 1976, depois da consolidação do partido nos principais municípios da região. Por esta razão o único partido de oposição teve participação marginal na política caraguatatubense, diferindo-se dos municípios do interior, onde se constituiu na porta de entrada para os grupos políticos emergentes que não conseguiam espaço entre os políticos tradicionais, conforme argumenta Kerbauy (2000, p. 69).
} 
Municipal. Eram eles os "adhemaristas", que apoiavam e recebiam suporte do deputado federal Adhemar de Barros Filho, e os "bonequistas", liderados pelo influente ex-prefeito Geraldo Nogueira da Silva, conhecido como Boneca. A dinâmica política girou em torno desses dois grupos até a década de 1980, quando o fim do bipartidarismo amplia o campo político e permite maior participação em nível partidário.

Neste segundo momento ocorre um rearranjo nas forças políticas locais ao mesmo tempo em que surge uma nova realidade social e econômica marcada pela ascensão das atividades comerciais e de serviço e pelo aumento populacional, caracterizado especialmente pela chegada maciça de migrantes. As novas exigências em termos de capital político contribuíram para a nova formatação do campo político, com a permanência daqueles que melhor souberam se adaptar à nova realidade, e com a entrada de novos agentes políticos com perfil distinto daqueles que estavam saindo. A diminuição da atuação de órgãos ligados ao governo estadual, fundamental na constituição do capital político de vários agentes, também contribuiu para esta mudança. Esta nova formatação se consolida na década de 1990, com a presença majoritária de agentes oriundos do setor de comércio e serviços, cujas atividades estão ligadas direta e indiretamente ao turismo. São eles com maiores possibilidades para mobilizarem o montante necessário de recursos econômicos para financiar campanhas eleitorais cada vez mais caras. Em comum nesses três momentos apenas há o fato de a oposição ao status quo estadual ter papel marginal na política local, tanto pela dependência que o município tinha dos recursos estaduais, quanto pela própria fragilidade da oposição em âmbito regional.

\section{COMPOSIÇÃO SOCIAL DA ELITE POLÍTICA}

Abordaremosnestaseçãocomo era operfil social dos principais agentespolíticos em Caraguatatuba, mais especificamente dos vereadores, no período que compreende os anos de 1970 a 2000. Serão considerados aqui os vereadores eleitos e os suplentes que assumiram o cargo durante a legislatura, ficando de fora os demais suplentes. Os dados apresentados a seguir nos permitem identificar a representatividade social, as bases políticas e possíveis fatores que possam ter contribuído para a transformação do perfil social no período enfocado (de 1970 a 2000).

Os dados apresentados na tabela 1 servirão de base para a argumentação que segue. 
Tabela 1 - Composição social dos vereadores

\begin{tabular}{|c|c|c|c|}
\hline Profissão anterior & & \multicolumn{2}{|c|}{ Idade no início do primeiro mandato } \\
\hline Comerciante/empresário & 22 & Menos de 30 anos & 09 \\
\hline Funcionário público & 16 & De 31 a 40 anos & 37 \\
\hline Profissional liberal & 08 & De 41 a 50 anos & 13 \\
\hline Professor & 03 & Mais de 50 anos & 06 \\
\hline Outros & 16 & & \\
\hline Local de nascimento & & \multicolumn{2}{|c|}{ Número de mandatos } \\
\hline Caraguatatuba & 21 & Um & 28 \\
\hline Litoral Norte e V. Paraíba & 16 & Dois & 15 \\
\hline Capital e interior/SP & 14 & Três & 15 \\
\hline Outros estados & 14 & Quatro & 07 \\
\hline \multicolumn{4}{|l|}{ Escolaridade* } \\
\hline Ensino Fundamental & 24 & & \\
\hline Ensino Médio & 20 & & \\
\hline Ensino Superior & 18 & & \\
\hline
\end{tabular}

(*) Não foi possível obter dados para a escolaridade de três vereadores do período 1969-1972

Fonte: Autor

Notamos, em primeiro lugar, a proeminência de vereadores que eram comerciantes ou empresários e funcionários públicos, com um relativo número de profissionais liberais e um pequeno número de professores. A categoria "outros", embora seja significativa, é heterogênea, pois nela estão alocados diversos tipos de profissionais tais como trabalhadores manuais qualificados (por exemplo, bancários e técnicos em contabilidade), autônomos, motoristas, pescadores, etc. Tanto a categoria "comerciantes/empresários" quanto a categoria "funcionários públicos" são fundamentais para nossa argumentação, conforme veremos adiante.

Quanto ao local de nascimento, verificamos que a maior parte dos vereadores nasceram na região, embora seja significativa 0 número dos que vieram de longe. A migração tem grande importância na transformação social e econômica pela qual passou Caraguatatuba no período estudado, e isso também se reflete no grande número de migrantes que compõe a elite política local. Porém, deve-se ressaltar que havia um processo anterior de migração no qual indivíduos de riqueza mediana adquiriam propriedades em Caraguatatuba e acabavam por ali se instalar, abrindo algum tipo de negócio ou realizando algum tipo de serviço. Eram geralmente profissionais liberais ou funcionários dos empreendimentos que se realizavam na região nesse período, especialmente aqueles ligados às 
atividades portuárias em São Sebastião. Eles acabavam entrando nas altas rodas sociais e alguns deles terminavam por exercer algum tipo de atividade política, principalmente se em seu município de origem já tivesse alguma atuação política.

Em relação à escolaridade, não há grandes disparidades entre os três níveis de ensino. Considerando o nível educacional como indicativo de uma posição social mais elevada, poderíamos inferir que há uma maior representação dos estratos mais elevados da população em detrimento da representação dos estratos mais baixos. Relacionando escolaridade e profissão, notaremos que a maior parte dos comerciantes/empresários e funcionários públicos têm até o Ensino Médio, e que aqueles que possuem Ensino Superior são, em sua maioria, profissionais liberais e professores, embora exista entre eles um número significativo de funcionários públicos (ver tabela 2). 0 que chama atenção nessa relação é o grande número de funcionários públicos com apenas o Ensino Fundamental, indicando que eles pertenciam aos escalões baixos e médios do serviço público.

Tabela 2 - Relação entre profissão anterior e escolaridade*

\begin{tabular}{|l|c|c|c|c|c|}
\hline & $\begin{array}{c}\text { Comerciantes/ } \\
\text { Empresários }\end{array}$ & $\begin{array}{c}\text { Funcionários } \\
\text { públicos }\end{array}$ & $\begin{array}{c}\text { Profissionais } \\
\text { liberais }\end{array}$ & Professores & Outros \\
\hline Fundamental & 8 & 8 & 0 & 0 & 8 \\
\hline Médio & 10 & 2 & 0 & 0 & 8 \\
\hline Superior & 2 & 5 & 8 & 3 & 0 \\
\hline
\end{tabular}

(*) Não foi possível obter dados para a escolaridade de três vereadores do período 1969-1972

Fonte: Autor

Os vereadores iniciavam seu primeiro mandato com idade entre 31 e 40 anos, e a média de idade por legislatura ficava em torno de 41 anos. Há de se destacar que um número significativo de vereadores que possuíam Ensino Superior (6 em 18) tiveram seu primeiro mandato antes dos 30 anos, enquanto que pouco mais de um terço dos vereadores que possuíam o Ensino Fundamental (10 em 24) se elegeram pela primeira vez com mais de 41 anos. Dessa maneira, o nível educacional aparece como um fator condicionante para a entrada na política no sentido de que, quanto maior a escolaridade menor a idade e vice-versa.

Quanto ao número de mandatos, verifica-se que grande parte dos vereadores exerceu apenas um ou dois mandatos. A média de renovação da Câmara por legislatura ficou em torno de 54\% nesse período. 0 que chama a atenção é o número de funcionários públicos que conseguiam se reeleger duas ou 
mais vezes, 8 dos 16. A maior parte deles fez sua carreira política nas décadas de 1960 e 1970, justamente no período em que os órgãos estaduais já citados tiveram maior atuação no município. Dos comerciantes e empresários, por exemplo, apenas 07 dentre os 22 conseguiam mais de dois mandatos. Esses dados sugerem que a presença de funcionários públicos, sobretudo na década de 1990, deveu-se mais às reeleições do que à renovação dos quadros políticos por indivíduos que desempenhavam tal profissão antes. De fato, o único caso de um funcionário público que se elegeu pela primeira vez nas eleições de 1992 já tinha um histórico de participação política desde a década de 1960, quando chegou a ser suplente da Câmara Municipal, embora não tenha disputado todas as eleições nesse período.

Em relação aos comerciantes e empresários, nota-se que a maior parte deles (12 dos 22) teve seu primeiro mandato na década de 1990, período em que se consolidam as mudanças econômicas que vinham acontecendo desde as décadas anteriores. Com a atividade turística se tornando o motor da economia local, aumenta a participação política de indivíduos ligados a esses setores. Na tabela 3 percebemos um processo de inversão na representação profissional da Câmara Municipal ocorrida a longo desses trinta anos: de uma Câmara composta por funcionários públicos e profissionais liberais nos anos 1970, para uma Câmara composta principalmente por comerciantes e empresários nos anos 1990, sendo a década de 1980 um período de transição.

Tabela 3 - Profissão anterior por legislatura

\begin{tabular}{|c|c|c|c|c|c|}
\hline & $\begin{array}{c}\text { Comerciantes/ } \\
\text { Empresários }\end{array}$ & $\begin{array}{c}\text { Funcionários } \\
\text { públicos }\end{array}$ & $\begin{array}{c}\text { Profissionais } \\
\text { liberais }\end{array}$ & Professores & Outros \\
\hline $1969-1972$ & 2 & 3 & 2 & 1 & 1 \\
\hline $1973-1976$ & 2 & 5 & 2 & 1 & 3 \\
\hline $1977-1982$ & 3 & 5 & 2 & 1 & 0 \\
\hline $1983-1988$ & 3 & 3 & 3 & 0 & 4 \\
\hline $1989-1992$ & 4 & 4 & 2 & 0 & 8 \\
\hline $1993-1996$ & 6 & 5 & 2 & 1 & 3 \\
\hline $1997-2000$ & 10 & 1 & 1 & 1 & 4 \\
\hline
\end{tabular}

Fonte: Autor

Na década de 1970, a presença de autarquias e empresas estatais atuando de maneira direta e constante no município favoreceu, em certa medida, o recrutamento político entre seus funcionários, assim como o maior peso relativo dos profissionais liberais neste período se relaciona à sua proeminência social num 
município com uma população pequena, concentrada, homogênea e pobre. Na década de 1980, há grande presença de vereadores alocados na categoria "outros", o que indica maior abertura do campo político, embora muitos deles tenham permanecido no cargo por um ou dois mandatos. Na década de 1990, conforme já destacamos, há uma acentuada diminuição no recrutamento de funcionários públicos, sendo a maioria deles vereadores que vinham sendo reeleitos desde a década anterior, ou seja, que já possuíam capital político acumulado. Os novos membros da Câmara, por outro lado, constituíam-se em empresários e comerciantes que, capazes de mobilizar sobretudo recursos econômicos para custear as campanhas eleitorais cada vez mais caras, mudaram a feição do legislativo local.

Outro indicador da mudança do perfil social da elite política é a diminuição do peso relativo dos vereadores que possuíam maior escolaridade. De acordo com o gráfico 1, há uma queda acentuada do peso relativo dos vereadores com Ensino Superior a partir da década de 1980, atingindo seu ponto mínimo na legislatura 1997-2000, enquanto que ocorre um ligeiro crescimento do Ensino Fundamental e um crescimento um pouco mais acentuado do ensino médio. Embora tenha se mantido constante o número de vereadores oriundos de profissões que requer maior escolaridade, como professores e profissionais liberais, as novas cadeiras que surgiram com o aumento do número de vereadores acabaram por serem ocupadas por vereadores provenientes de outros estratos sociais.

Gráfico 1 - Peso relativo da escolaridade* por legislatura (\%)

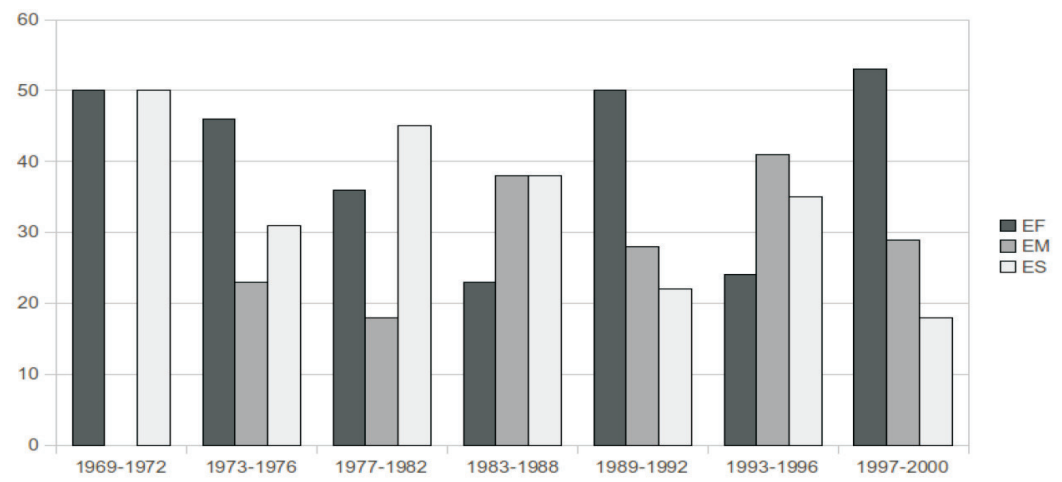

(*) Não foi possível obter dados para a escolaridade de três vereadores do período 1969-1972

Fonte: Autor 
Outro ponto interessante é a relação entre a escolaridade e o local de nascimento. Enquanto que para o Ensino Médio e o Ensino Superior há um equilíbrio, para o Ensino Fundamental há um número consideravelmente maior de vereadores nascidos em Caraguatatuba e na região do que o número daqueles que nasceram em outras regiões do Estado de São Paulo e em outros estados, o que pode ser explicado pela ausência de instituições de ensino superior no Litoral Norte, embora elas existam nos principais municípios do Vale do Paraíba. Verificamos também um número grande de funcionários públicos nascidos em Caraguatatuba ou no Litoral Norte e Vale do Paraíba, enquanto que os profissionais liberais vieram majoritariamente da região metropolitana de São Paulo.

0 período analisado tem como importante característica uma constante renovação dos membros da Câmara. Praticamente em todas as eleições realizadas mais da metade dos eleitos eram novatos, indivíduos que assumiam seu primeiro mandato, e, por esse mesmo motivo, eram poucos aqueles que conseguiam se reeleger duas ou mais vezes. Portanto, em que medida essa renovação significou uma mudança efetiva do perfil social dos membros da Câmara? Em outras palavras, os novos agentes políticos refletiram de certo modo as transformações que ocorreram no município ou a renovação significou apenas a troca de nomes?

Recapitulando, o fim do bipartidarismo amplia as possibilidades de participação política em nível partidário como também, se considerarmos os impactos que essa mudança teve na política regional, permite novas oportunidades para a construção de alianças com líderes regionais emergentes. 0 rápido aumento populacional traz dificuldades para a manutenção das alianças locais já estabelecidas e a utilização de trunfos antigos frente a um eleitorado de feições novas. 0 aumento populacional também provoca 0 encarecimento das campanhas eleitorais, além da dificuldade extra em criar identificação em um eleitorado heterogêneo, formado por pessoas provenientes de outras regiões. Nessas circunstâncias, o sucesso eleitoral dependia da melhor adaptação às novas condições de disputa política, que envolvia a construção de um capital político distinto e mais variado que o necessário na situação anterior. É nesse sentido que os espaços políticos, sejam eles novos ou aqueles deixados pelos funcionários públicos, são ocupados pelos empresários e comerciantes, oriundos do setor da economia em ascensão e com capacidade para mobilizar os recursos financeiros necessários para custear as campanhas mais caras. Os funcionários, por sua 
vez, perdem um capital político importante com a diminuição da presença das autarquias e empresas estaduais no município.

0 capital político era constituído por uma combinação de outros tipos de capitais adquiridos em esferas diversas, tais como certa notoriedade social (que pode ser resultante de sua atuação profissional), relacionamentos construídos em vários ambientes (associações, sindicatos, ou até mesmo no exercício da profissão), militância partidária, acordos e alianças políticas envolvendo apoios mútuos, reconhecimento de sua atuação política, etc. A reconversão desses capitais dependia, por sua vez, da situação social e econômica do município, de modo geral, e de como o campo político está configurado em determinado momento, de modo específico.

Vejamos, por exemplo, o recrutamento de funcionários públicos. A importância de órgãos como o DER, a Sudelpa, a Sabesp e outros, sobretudo nas décadas de 1960 e 1970, relacionam-se com a estagnação econômica e a necessidade de recuperação do município após a catástrofe de 1967. Por um lado, esses órgãos possuíam certo reconhecimento por parte da população devido a suas atividades no município, as quais seus funcionários poderiam "pegar emprestado" para fins eleitorais. Por outro lado, a própria natureza da profissão, num município com uma economia pouco diversificada e estagnada, colocava esses indivíduos em uma posição social distinta. Podemos considerar este um dos fatores para a entrada na política de alguns funcionários.

Porém, conforme notamos anteriormente, os funcionários não pertenciam necessariamente aos escalões mais altos dos órgãos em que trabalhavam, portanto, não exerciam funções de direção que lhes pudessem proporcionar certa capacidade de influência. Sendo funcionários dos escalões médios e baixos, eles tinham, por outro lado, maior contato com a população e poderiam fazer esse papel intermediário entre os diretores (que têm a capacidade de decidir) e os usuários dos serviços ou os destinatários das obras. E essa posição peculiar pôde ser utilizada, no sentido das possibilidades de reconversão das relações estabelecidas em sua atuação profissional, como um trunfo político. Todavia, deve-se ressaltar que este capital não foi o único utilizado pelos funcionários, sendo mais provável sua combinação com outros tipos de capital para a obtenção de sucesso eleitoral.

Na década de 1980 esta combinação de capitais se torna insuficiente para garantir o sucesso eleitoral, pois o alargamento do campo político torna mais complexa a tarefa de constituir alianças, e a diminuição da atuação dos órgãos 
estaduais faz com que se tornem reduzidas as chances de reconversão das relações estabelecidas no exercício desta profissão. Notamos que a presença de funcionários públicos com menor escolaridade se deu justamente nas décadas de 1960 e 1970, enquanto que na década de 1980 aparecem os de maior escolaridade. Dos oito que possuem apenas o Ensino Fundamental, apenas três se elegeram pela primeira vez na década de 1970, e nenhum deles na de 1980; os outros cinco tiveram seu primeiro mandato na década de 1960. Daqueles com ensino médio e superior, apenas um teve seu primeiro mandato antes de 1983 (embora entre aqueles que se elegeram depois, um deles teve participação na política local desde a década de 1960).

A categoria "comerciantes e empresários" é composta por aqueles que desenvolvem algum tipo de atividade comercial ou de prestação de serviços, como os construtores (ou empreiteiros). Em outras palavras, seriam donos de estabelecimentos comerciais ou empresas de prestação de serviços. Os dados sugerem que a participação de comerciantes e empresários na política local cresce ao longo dos anos, principalmente na década de 1990. A tabela 3 dá a dimensão deste crescimento. Além disso, constatamos que 55\% deles se elegeram pela primeira vez ou nas eleições de 1992 ou na de 1996. 0 crescimento da participação dos comerciantes e empresários acompanha, portanto, o crescimento deste setor na economia local. Mas, antes não haveria condições para uma maior participação política?

Verificamos que antes de 1990 alguns nomes ligados à associação comercial chegaram a se candidatar a vereador, ainda que sem sucesso. Não existiam muitas oportunidades para participação política devido à polarização e estreiteza do campo político, situação que se manteve até o fim do bipartidarismo, quando novos espaços dentro do campo foram abertos, permitindo a entrada de novos agentes. Há também a questão do poder econômico dos comerciantes e empresários. Se considerarmos as dimensões dos negócios e as possibilidades de crescimento deles de acordo com os condicionantes econômicos locais, notaremos que aqueles da década de 1970 possuíam pequenos negócios e uma capacidade limitada para mobilizar recursos financeiros, contrastando com a maior dimensão dos negócios, especialmente na década de 1990. Portanto, o aumento da participação de comerciantes e empresários se relacionado, por um lado, ao alargamento do campo político e, por outro, à maior capacidade de mobilização de recursos financeiros para o custeio das campanhas. Porém, sendo este um 
fator significativo, não podem ser desconsiderados outros fatores para a formação do capital político, principalmente a capacidade para se articular com líderes comunitários e de criar identificação com a crescente população dos bairros, já que a fisionomia populacional de Caraguatatuba não era mais aquela do início da década de 1970.

Foi considerada aqui a atividade profissional de um vereador como um indicativo de sua inserção social, mais do que um aspecto determinante na formação da elite política local. Outros fatores concorriam para atuação política deste ou daquele vereador que propriamente sua atividade profissional. Por exemplo, a participação em clubes ou associações diversas, como o Rotary, o Lions ou o Esporte Clube XV de Novembro, sobretudo nos anos 1970 quando o peso da "alta sociedade" era maior num contexto de poucos eleitores concentrados no centro urbano. Por outro lado, desenvolver relações com líderes comunitários e criar identificação com bairros e regiões se tornou importante quando o eleitorado se tornou maior, heterogêneo e espalhado por diversos bairros, não apenas na área central. A constituição desses recursos como capital político foi importante para o sucesso eleitoral de vários vereadores. Há vários exemplos de vereadores que utilizaram uma combinação de reputação profissional, relações estabelecidas com movimentos sociais, associações desportivas e religiosas, para se firmarem como lideranças políticas locais.

\section{Conclusões}

0 conjunto das transformações econômicas e sociais ocorridas em Caraguatatuba, como também as mudanças institucionais ocorridas no país, redefiniram o campo político local ao alterarem as condições de acesso e de sucesso nele. Porém, a maneiras como os elementos se combinam e interagem uns com os outros condicionaram a maneira como se realizou a mudança dos principais agentes políticos, na que gradualmente ascendiam agentes de perfil social distinto dos antigos, sem resultar numa disputa entre os novos políticos e os já estabelecidos.

0 campo político, no início da década de 1970, era estreito e relativamente fechado devido primeiro à existência de apenas um partido, a Arena, e segundo pela polarização entre duas facções rivais pelo controle da prefeitura. Além de existir apenas um partido como opção para atuação política, ser filiado a ele 
era fundamental para conseguir negociar junto aos governos estadual e federal, em um contexto de centralização administrativa e forte repressão política, os recursos necessários para reconstrução do município após 1967 e para ampliar a infraestrutura necessária ao atendimento da crescente população que se instala na zona urbana do município. De qualquer forma, os agentes políticos eram impelidos a se filiarem à Arena, não importando suas concepções ideológicas ou políticas.

A polarização era outro fator que tornava relativamente fechado 0 campo político. Como vimos, existiam duas facções rivais na década de 1970: os adhemaristas e os bonequistas. 0 fim do bipartidarismo mudou essa situação, ao permitir o rearranjo das forças políticas pelos novos partidos que se criaram, possibilitando novas alternativas para construção de alianças tanto entre os agentes políticos locais quanto com relação aos líderes regionais que despontavam, principalmente com o crescimento do PMDB em todo o Estado de São Paulo. A polarização adhemaristas versus bonequistas deixa de ter sentido, até mesmo pelo enfraquecimento da posição de Boneca enquanto importante interlocutor entre 0 município e os governos estadual e federal, quando passa a disputar esta posição com outros líderes que antes tinham atuação política limitada como também com os novos líderes que surgiam com a ampliação das possibilidades de atuação partidária.

0 crescimento do eleitorado também é fator fundamental para as mudanças. Conforme notamos, Caraguatatuba teve um crescimento populacional acentuado durante esses trinta anos, resultante de um grande fluxo de migrantes que lá se estabeleceram. Como consequência politica, em primeiro lugar, obriga os agentes políticos a desenvolverem novas estratégias para sua legitimação, tendo em vista as novas características adquiridas pelo eleitorado. Em segundo lugar, os bairros que surgem com a fixação dessa população recém-chegada se tornam um campo fértil para o surgimento de novas lideranças, pelas demandas que eles trazem e pela construção de elos sociais e políticos com os novos moradores. Em terceiro lugar, o aumento do número de eleitores e do território ocupado por eles resulta no encarecimento das campanhas. A simplicidade das campanhas da década de 1970, baseadas em comícios na praça e panfletagem, cede espaço para campanhas mais bem elaboradas, com os comícios indo para os bairros, com a confecção de material de campanha mais elaborados e diversificados (camisetas, adesivos, brindes, etc.), recursos para verificação da receptividade da 
campanha pelos eleitores, etc. Os agentes políticos devem, portanto, ter condições para mobilizar a quantidade de recursos financeiros necessários para custear as campanhas eleitorais, algo que se torna cada vez mais complexo.

Os dois fatores abordados até aqui, o fim do bipartidarismo e o aumento do eleitorado, acontecem quase que simultaneamente na década de 1980. Eles não levam a uma substituição imediata dos antigos vereadores pelos novos, mas indicam uma mudança gradual que se inicia nessa época e que se consolida na década seguinte. Os antigos líderes aos poucos perdem espaço e se retiram da arena política, e seus substitutos não são os seus herdeiros políticos ou pessoas que compartilham de certa forma as mesmas ideias e a mesma visão do município e de seus problemas. Processos de mudança nas elites políticas, como no caso estudado por Bilac (2001), não significa um processo de ruptura com as antigas elites, sendo, ao contrário, mudanças efetuadas sob o controle dessas mesmas elites, implicando na substituição dos antigos líderes por novos mais afeitos às atuais circunstâncias, existindo, porém, um caráter de continuidade entre ambas. Em todo o caso, as mudanças na elite pode ser resultado de um processo de transformação interna delas que propriamente a troca de uma elite por outra. No caso de Caraguatatuba, se não houve uma ruptura entre a elite dos anos 1970 e a elite dos anos 1990, não podemos dizer que houve uma continuidade; elas possuem características distintas quanto sua origem social, inserção política e visão do município como um todo. A substituição de uma por outra se deu de forma gradual, com a aposentadoria dos antigos e a chegada dos novos, acompanhando o processo de transformação geral que acontecia no município.

\section{REFERÊNCIAS}

AROUCA, Justo. Memorial de sua excelência: história política de Caraguatatuba. Caraguatatuba: FUNDACC, 2003.

BILAC, Maria Beatriz Bianchini. Elites políticas de Rio Claro: recrutamento e trajetória. Piracicaba: Unimep; Ed. da Unicamp, 2001.

BOURDIEU, Pierre. O poder simbólico. 2. ed. Lisboa: Difel, 1989.

. As elites como objeto de estudo. In: CORADINI, Odaci Luiz (Org.). Estudos de grupos dirigentes no Rio Grande do Sul: algumas contribuições recentes. Porto Alegre: Ed. da UFRGS, 2008. 
DEAN, Warren. Rio Claro: um sistema brasileiro de grande lavoura, 1820-1920. Rio de Janeiro: Paz e Terra, 1977.

INSTITUTO DE PESQUISAS TECNOLÓGICAS DE SÃO PAULO. Relatório técnico $n^{\circ}$ 46.172. Diagnóstico da situação dos recursos hídricos das bacias hidrográficas do litoral norte de São Paulo. São Paulo: IPT, 2000. v. 1.

KERBAUY, Maria Teresa Miceli. A morte dos coronéis: política interiorana e poder local. São Paulo: Cultura Acadêmica, 2000.

LEAL, Vitor Nunes. Coronelismo, enxada e voto. 2. ed. São Paulo: Alfa-Ômega, 1975.

LOVE, Joseph. A locomotiva: São Paulo na federação brasileira (1898-1937). Rio de Janeiro: Paz e Terra, 1982.

QUEIROZ, Maria Isaura Pereira de. 0 mandonismo local na vida política brasileira. São Paulo: Instituto de Estudos Brasileiros/USP, 1969.

SÃO PAULO. Secretaria do Meio Ambiente. Macrozoneamento do Litoral Norte: plano de gerenciamento costeiro. São Paulo, 1996.

. Poder local: conceito e exemplos de estudos no Brasil. Revista Sociedade \& Natureza, Uberlândia, v. 20, n. 2, dez. 2008. 